\title{
Examining the dark recesses of the heart: Technology drives innovation
}

\author{
Malini Daniel, MD, and Pavan Atluri, MD
}

\footnotetext{
From the Division of Cardiovascular Surgery, Department of Surgery, University of Pennsylvania School of Medicine, Philadelphia, Pa.

Disclosures: Authors have nothing to disclose with regard to commercial support.

Received for publication March 23, 2017; accepted for publication March 24, 2017; available ahead of print April $18,2017$.

Address for reprints: Pavan Atluri, MD, Assistant Professor of Surgery, Director, Minimally Invasive and Robotic Cardiac Surgery, Director, Heart Transplant and Mechanical Circulatory Support, University of Pennsylvania, 6 Silverstein Pavilion, 3400 Spruce St, Philadelphia, PA 19104 (E-mail: Pavan.atluri@uphs.upenn.edu).

J Thorac Cardiovasc Surg 2017;154:22-3

$0022-5223 / \$ 36.00$

Copyright (c) 2017 by The American Association for Thoracic Surgery

http://dx.doi.org/10.1016/j.jtcvs.2017.03.109
}

With the advent of more advanced aortic valve repair techniques for indications that span the spectrum of cusp pathology, the indications for and number of performed valve-sparing root replacements have increased as more surgeons are attempting these operations with increasing frequency. ${ }^{1}$ Valve-sparing aortic root replacement is a complex procedure, with outcomes that vary highly according to the experience and expertise of the surgeon. ${ }^{2-4}$ Should more objective intraoperative data to guide technique be developed, more surgeons might then be able to perform this procedure with better early and late outcomes, thereby leveling the field. This in turn could allow more patients to avoid lifelong anticoagulation while, with technical improvement, limiting the need for reoperation. ${ }^{5}$ In this issue of the Journal, Miyahara and colleagues ${ }^{4}$ attempt to work toward this noble goal by providing more rigorous data for intraoperative assessment of the aortic valve to supplement the current standard of intraoperative visualization of the valve and postbypass transesophageal echocardiography in the hope of improving early and late outcomes for valve-sparing root replacement surgery. ${ }^{4}$

Miyahara and colleagues ${ }^{4}$ detail 36 cases in which a flexible left ventricular videoscope (LV-VS) was used intraoperatively to guide the determination of initial need for aortic valve repair during valve-sparing root replacement as well as to assess the need for revision of the repair. In their technique, the LV-VS is inserted through the right superior pulmonary vein and guided through the mitral valve to visualize the ventricular side of the aortic valve. In combination with root pressurization on the aortic side of the valve, this allows visualization of the degree of aortic insufficiency and cusp pathology before repair (to guide repair choice) and after repair (to determine the need for revision of the repair before bypass is discontinued). What Miyahara and colleagues ${ }^{4}$ do not show is a true advantage to their use of LV-VS relative to the current standard of assessment of the aortic valve, ultimately claiming noninferiority relative to the current standard involving valve repair.

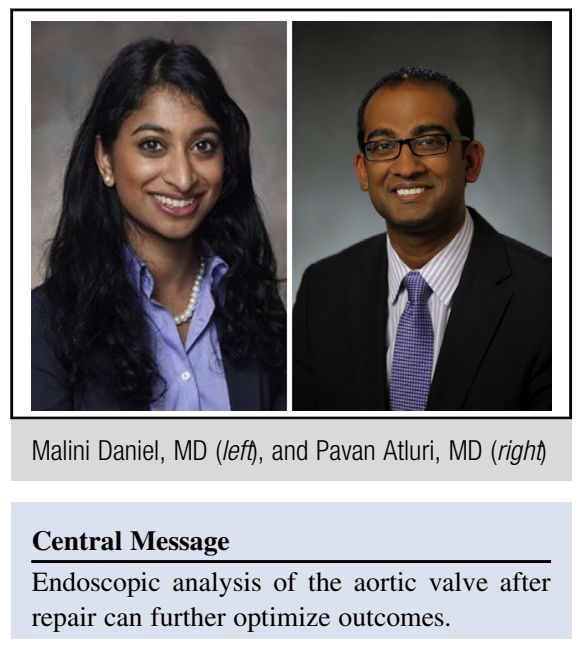

See Article page 24.

both intraoperative visual assessment with traction on the aortic valve and transesophageal echocardiography, as best described by Boodhwani and colleagues. ${ }^{6}$

We have learned from the seminal imaging work of Le Polain de Waroux and associates ${ }^{7}$ that the 3 most important parameters for a durable repair are (1) the absence of more than mild residual aortic insufficiency, (2) a coaptation length greater than $4 \mathrm{~mm}$, and (3) demonstration of Shäffer's effective height concept $^{8}$ meaning coaptation height starting well above the plane of the aortic annulus. ${ }^{9}$ LV-VS can help provide an intraoperative assessment of 2 of these critical factors, the degree of aortic insufficiency and the effective height. LV-VS is able to help determine mild to moderate aortic insufficiency, but a major limitation of this technique is that with "significant" aortic insufficiency, there is too much flow directed at the videoscope for adequate visualization of cusp pathology to direct repair. ${ }^{4}$

There may be some point along the spectrum of aortic insufficiency where there would be a moderate degree of aortic insufficiency that would allow LV-VS determination of cusp pathology, which could provide information toward determining revision repair techniques. And although Miyahara and colleagues ${ }^{4}$ currently only show noninferiority to current standard valve assessment, the potential remains for future technical and technologic refinements, potentially with computer-aided structural analysis, that could conceivably allow surgeons increasingly to use advanced endoscopic techniques to guide 
More information to help guide operative technique and limit early and late failure for a procedure as complicated as valve-sparing aortic root replacement would be greatly welcomed and could be of great long-term benefit to patients wishing to avoid anticoagulation and reoperation. Miyahara and colleagues ${ }^{4}$ are to be congratulated on their innovative use of novel technology to drive further valvesparing root replacement techniques. Innovations such as those that they describe will continue to ensure the long-term advancement and success of this complex and very rewarding operation. Further incorporation of technology with standardization of techniques may allow more widespread delivery of valve-sparing aortic root replacement procedures, with the potential for greater patient benefit.

\section{References}

1. David T. Current readings: aortic valve-sparing operations. Semin Thorac Surg. 2014;26:231-8.
2. Schneider U, Feldner SK, Hofmann C, Schöpe J, Wagenpfeil S, Giebels C, et al Two decades of experience with root remodeling and valve repair for bicuspid aortic valves. J Thorac Cardiovasc Surg. 2017;153:S65-71.

3. David TE, David CM, Feindel CM, Manlhiot C. Reimplantation of the aortic valve at 20 years. J Thorac Cardiovasc Surg. 2017;153:232-8.

4. Miyahara S, Oha T, Takahashi H, Inoue T, Matsumori M, Tanaka H, et al Feasibility of intraoperative water testing in aortic valve repair: direct visualization from left ventricle with a videoscope. J Thorac Cardiovasc Surg. 2017;154: 24-9.

5. Miller DC. Valve-sparing aortic root replacement in patients with the Marfan syndrome. J Thorac Cardiovasc Surg. 2003;125:773-8.

6. Boodhwani M, de Kerchove L, Watremez C, Glineur D, Vanoverschelde J, Noirhomme P, et al. Assessment and repair of aortic valve cusp prolapse: implications for valve-sparing procedures. J Thorac Cardiovasc Surg. 2011;141: 917-25.

7. Le Polain de Waroux J, Pouleur A, Robert A, Pasquet A, Gerber B, Noirhomme P, et al. Mechanisms of recurrent aortic regurgitation after aortic valve repair: predictive value of intraoperative transesophageal echocardiography. JACC Cardiovasc Imaging. 2009;2:931-9.

8. Schäfers HJ, Bierbach B, Aicher D. A new approach to the assessment of aortic cusp geometry. J Thorac Cardiovasc Surg. 2006;132:436-8.

9. Van Dyck M, Glineur D, de Kerchove L, El Khoury G. Complications after aortic valve repair and valve-sparing procedures. Ann Cardiothorac Surg. $2013 ; 2: 130-9$.

Access to The Journal of Thoracic and Cardiovascular Surgery Online is reserved for print subscribers!

Full-text access to The Journal of Thoracic and Cardiovascular Surgery Online is available for all print subscribers. To activate your individual online subscription, please visit The Journal of Thoracic and Cardiovascular Surgery Online, point your browser to http://www.mosby.com/jtcvs, follow the prompts to activate your online access, and follow the instructions. To activate your account, you will need your subscriber account number, which you can find on your mailing label (note: the number of digits in your subscriber account number varies from 6 to 10 ). See the example below in which the subscriber account number has been circled:

\section{Sample mailing label}

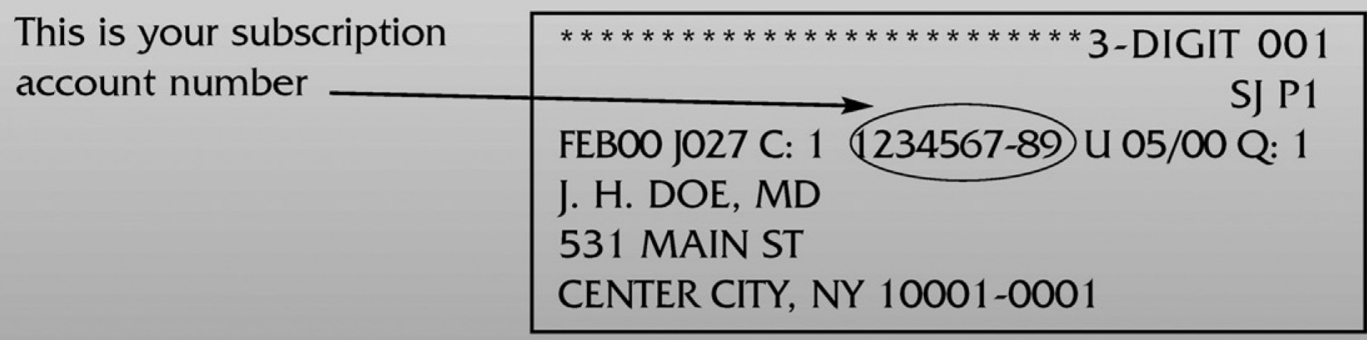

Personal subscriptions to The Journal of Thoracic and Cardiovascular Surgery Online are for individual use only and may not be transferred. Use of The Journal of Thoracic and Cardiovascular Surgery Online is subject to agreement to the terms and conditions as indicated online. 